\title{
Modification of the Leontief-Ford Input-Output Model for the Green Economy Goals and Environment Protection
}

\author{
Ivan Potravny ${ }^{1}$, Andrey Gusev ${ }^{1}$, Vasily Stoykov ${ }^{2}$, Violetta Gassiy ${ }^{3}$ \\ ${ }^{1}$ Plekhanov Russian University of Economics, Moscow, Russia \\ ${ }^{2}$ Moscow State University of Civil Engineering, Moscow, Russia \\ ${ }^{3}$ Kuban State University, Krasnodar, Russia \\ Email:vgassiy@mail.ru
}

How to cite this paper: Potravny, I., Gusev, A., Stoykov, V. and Gassiy, V. (2017) Modification of the Leontief-Ford Input-Output Model for the Green Economy Goals and Environment Protection. Journal of Geoscience and Environment Protection, 5, 15-23. https://doi.org/10.4236/gep.2017.511002

Received: October 15, 2017

Accepted: November 5, 2017

Published: November 8, 2017

Copyright $\odot 2017$ by authors and Scientific Research Publishing Inc. This work is licensed under the Creative Commons Attribution International License (CC BY 4.0).

http://creativecommons.org/licenses/by/4.0/

\begin{abstract}
The economics' ecological modernization approach based on the input-output balance model is considered in the paper. The government measures on Russian Federation's transition to green economy on reducing of greenhouse gas emissions are analyzed. In an article for green economy evaluation, including greenhouse gas emissions per capita and per unit of GDP, the indicator of the production environmental costs is proposed to include. The authors suppose adding and to modernize the Leontief-Ford model of input-output balance by economic evaluation of the environment pollution effects. This model is proposed to consider macro-economic assessment of environmental damage, health deterioration due to environmental pollution, as well as the use costs of the environmentally friendly technologies, the environmental and energy innovations' implementation, climate change. The proposed modified model of environmentally oriented input-output balance can be used in the economic compensation system implementation on natural capital use and ecosystem services' consuming in countries and their regions. The modified Leontief-Ford model proposed in the paper can be used for green economy development calculating, for example in Russia during the development of measures for the environment and economic development. Also this paper opens discussions for opportunities of the further possible integration of the theoretical models for environment protection decision-making.
\end{abstract}

\section{Keywords}

Ecological Modernization of Economy, Economic Loss, Environmental Pollution, Green Economy, Leontief-Ford Model 


\section{Introduction}

At present, many countries including Russia realize measures for the green economy transition which is defined as an economy improving the welfare and ensuring social justice at the same time significantly reducing environmental risks. Green economy is often understood as an economy with low emissions of greenhouse gases. It is estimated that soon the key definition for the advanced economies of the world will be low carbon economy with high energy efficiency and minimal impact on the climate system. Russia commits greenhouse gas emissions' neutralizing not only for itself but even for other countries. Since 1990 , the country has greatly reduced the volume of harmful emissions into the atmosphere. Now the Russian throws only $6 \%$ of the global cycle.

The role of Russia as the world's largest absorber of greenhouse gases and global environmental donor is extremely high, so there is an interest in promoting the ideology of economic compensation for environmental services. Other countries have also a great potential in the environment protection. For example, the countries of the Asia-Pacific Economic Cooperation have significant potential of tropical forests as absorbers of greenhouse gases, and can rely on the application of the economic compensation system because their natural capital performs important ecosystem functions including the absorption and assimilation of greenhouse gases. In these circumstances the science and practice can integrate the approaches for environment protection problem-solving. The potential of combining two useful ecological-economic methods: input-output analysis and multi-criteria decision aid. By doing so, it assesses the sustainability of investment in various economic sectors, with the aim of minimizing resource use and generation of emissions [1].

\section{Materials and Methods}

One of the current problems is the climate change issues' account in the development of national and regional strategies, programs of social-economic development, researches as well as mechanisms' development for greenhouse gas emissions reducing.

For Russia the search for effective economic tools regulating greenhouse gas emissions is essential. Despite the measures taken and some stabilization of the situation in 2007-2014, apparently associated with the global crisis, the amount of greenhouse gas emissions per capita tends to increase, Table 1 .

Table 1. The amount of greenhouse gas emissions per capita and per unit of GDP (at current prices) in the Russian Federation.

\begin{tabular}{ccccccccc}
\hline Indicator & 2007 & 2008 & 2009 & 2010 & 2011 & 2012 & 2013 & 2014 \\
\hline $\begin{array}{c}\text { The amount of greenhouse gas emissions } \\
\left(\mathrm{CO}_{2} \text {-equivalent) per unit of GDP, bn. Rub. }\right.\end{array}$ & 49.19 & 40.19 & 38.00 & 57.97 & 49.68 & 45.74 & 41.33 & 41.1 \\
$\begin{array}{c}\text { The amount of greenhouse gas emissions } \\
\left(\mathrm{CO}_{2} \text {-equivalent) per capita, kg }\right.\end{array}$ & 11.5 & 11.6 & 10.3 & 16.2 & 16.6 & 16.9 & 16.4 & 16.3 \\
\hline
\end{tabular}

Source: State report "On condition and protection of the environment in Russian Federation in 2016". -Moscow, 2016, p. 13. 
Current research concerns the relationship between trade and climate change in the countries of Southeast Asia region, particularly Vietnam, Indonesia, Malaysia show the need to consider this factor in the green economy models development [2]. In assessing the development tendencies of "green" economy the appropriate indicators choice is much important for "green" growth determination as well as their use in management and development process of country or region. Lukyanchikov and Potravny analyze indicators used for the assessment of green economy development including the indicators of environmental intensity, environmentally adjusted gross domestic product (GDP), the rate of "pure" savings etc. [3]. During the organizing of United Nations Conference on Sustainable Development (Rio + 20, 2012) the report “Towards a Green Economy: Pathways to Sustainable Development and Poverty Eradication" was prepared. It stresses that GDP and other economic indicators are the "distorting lens" and they do not reflect the negative effects of economic activities on the welfare. The final good refers to such number of indicators [4]. One of the modeling tool by which you can explore the coordination of economic and environmental activities, is extended input-output model of balance. In the 1970s in the United States the economic structure impact on the environment was analyzed based on Leontief-Ford model [5]. However, this model didn't aim to assess the negative effects of the environment pollution due to economic development.

Here we propose a modification of the Leontief-Ford model presenting in detail the structure of the ecological-economic, ecological-technological parameters with the objectives of damage determination caused by environmental pollution. The ways of ecological and technological renewal of macroeconomic development are also explored. It should be noted that modified model contains a simplification in relation to the American model, which only refers to the description of air pollution. Firstly, it is due to the need for a clearer interpretation of the analytical results, and, secondly, the importance of considering the effect of the negative impact on the environment, especially air pollution on human health. This importance is determined by the largest specific gravity of health damage in the structure of the total economic damage caused by air pollution [6].

The modified model can be represented as the following system of equations:

$$
\sum_{j=1}^{m} a_{i j} x_{j}+\sum_{q=m+1}^{n} a_{i q} y_{q}+y_{i}=x_{i}, \quad i=\overline{1, m}
$$

where $i$-the type of a product. All these products can be from 1 (unit) to $m$; $m$-the number of all products.

$$
\sum_{j=1}^{m} a_{q j}^{j} x_{j}-y_{q}=b_{q}, \overline{q=m+1, n}
$$

where: $a_{i j}$-costs of product $i$ per unit of the production $j$;

$a_{i q}$-costs of product $i$ to render harmless a unit of hazardous waste $q$;

$a_{q}^{i}$-waste generation $q$ in production a unit of product $j$; 
$y_{i}$ - the value of the final good $i$;

$x_{i}$ and $x_{j}$-the value of gross domestic product of $i$-type or $j$-type;

$y_{q}$-the volume of waste disposal $q$ prevention of the potential air pollution by hazardous waste);

$b_{q}$-waste $q$ emissions into the air.

Equations (1), in contrast to the usual static balance model, the production cost and the air pollution prevention costs are separately considered. Equation (2) describes the ecological and technological balance of education, disposal and specific waste emissions.

Find out the conditions according which the system of Equations (1)-(2) has a non-negative solution in the variables $\left(x_{1}, \cdots, x_{m}, y_{m+1}, \cdots, y_{n}\right)$ by entering vectors and matrices:

$$
\begin{gathered}
x=\left(x_{1}, \cdots, x_{m}\right) ; \quad y=\left(y_{1}, \cdots, y_{m}\right) ; B=\left(b_{m+1}, \cdots, b_{n}\right) ; \\
\bar{y}=\left(y_{m+1}, \cdots, y_{n}\right) ; \quad A_{1}=\left\|a_{i j}\right\|_{m}^{n} ; A_{2}=\left\|a_{i q}\right\|_{m}^{n-m} ; A_{3}=\left\|a_{q}^{j}\right\|_{n-m}^{m}
\end{gathered}
$$

The model (1) - (2) can be written as:

$$
\begin{gathered}
\left(E-A_{1}\right) x-A_{2} \bar{y}=y \\
A_{3} x-\bar{y}=B
\end{gathered}
$$

where: $E$ - the identity matrix of appropriate dimension.

We expand contents of $A_{3}$ matrix. Each its element can be separated into the following ecological-technological parameters:

$$
a_{q}^{j}=\bar{a}_{q}^{j}+\overline{\bar{a}}_{q}^{j}
$$

where: $\bar{a}_{q}^{j}$-preventing part of waste $q$ formed in one production unit $j$;

$\overline{\bar{a}}_{q}^{j}$-emissions into the air of the not prevented part of waste $q$ per one production unit $j$.

We denote $\overline{A_{3}}=\left\|\bar{a}_{q}^{j}\right\|_{n-m}^{m}$ и $\overline{\overline{A_{3}}}=\left\|\overline{\bar{a}}_{q}^{j}\right\|_{n-m}^{m}$ then the Equation (4) can be rewritten as

$$
\left(\overline{A_{3}}+\overline{\overline{A_{3}}}\right) x-\bar{y}=B
$$

Substitute into the Equation (3) the expression for $\bar{y}$ from the Equation (5). With considering $\overline{\overline{A_{3}}} x=B$, after transformations we obtain

$$
\left[E-\left(A_{1}+A_{2} \overline{A_{3}}\right)\right] x=y
$$

In order for non-negative vector $y$ Equation (6) has a non-negative decision on the desired vector $x$, the following condition is sufficient: eigenvalues of matrix $\left(A_{1}+A_{2} \overline{A_{3}}\right) \geq 0$ are less than 1 [7]. For this purpose, in case of matrix in decomposability it is enough that

$$
\sum_{i=1}^{m}\left(a_{i j}+\sum_{q=m+1}^{n} a_{i q} \bar{a}_{q}^{j}\right) \leq 1, \quad j=\overline{1, m}
$$

Moreover, at least one of $j$ strict inequality must be satisfied. In a typical static 
balance model in terms of money (where the pollution costs are not separately allocated) the matrix rate of coefficients, as a rule, does not exceed one, and it is less than one for many products, that characterizes the production profitability. On the other hand, in the former Soviet Union the models were built in kind. There were many coefficients more than one, as per one unit tens and hundreds of other products' units could be spent. But if the original matrix is productive, it is always possible to change the coefficients' scale such that the sum of coefficients for each of the columns does not exceed the one and at least one of the columns is less than one [8].

In modified model the condition (2) is built on the basis of natural meters. Starting from the left side of the condition (7) the direct costs of the product $i$ for the unit $j$ production and the production pollution prevention $\bar{a}_{i j}$ are

$$
\bar{a}_{i j}=a_{i j}+\sum_{q=m+1}^{n} a_{i q} \bar{a}_{q}^{j}, i, j=\overline{1, m}
$$

The coefficients $a_{i j}$ and $a_{i q}$ are expressed in monetary form and $\bar{a}_{q}^{j}$ have natural meters. Such coefficients' diversity supposes that if it is necessary the built scale has to be changed (2).

Considering all mentioned above the matrix $A_{1}+A_{2} \overline{A_{3}}$ is productive, i.e. reflecting the system potential to reproduction, if the condition (7) is obtained. The equitation solution (6) is:

$$
\left[E-\left(A_{1}-A_{2} \overline{A_{3}}\right)\right]^{-1} y=x
$$

The $x$ values obtained from (8) are substituted into (4), as a result the values $\bar{y}$ are determined.

Consider the enhanced use of the modified model in relation to the input-output model. Thus, in the balance model the pollution costs are implicitly reflected in the coefficients $a_{i j}$. For example, electricity costs associated with the unit production of ferrous metallurgy include the costs of harmful impurities' rectification resulting during a unit production of ferrous metallurgy. In the matrix $A_{1}+A_{2} \overline{A_{3}}$ the coefficients $a_{i j}$ reflects only the production costs. The pollution costs allocation through the $a_{i q}$ coefficients' use allows more clearly planning environmental costs, depending on the options setting of the final good values. With the coefficients $\bar{a}_{q}^{j}$ it is possible to determine the negative effects of pollution by macro-economic damage assessment, which will be discussed below.

Because of the models' decision (1)-(2) it is possible to determine the economic damage (compensation costs) caused air pollution. The initial basis for damage indicators' calculation can become methods developed in Russia, such as The Methodology adopted in 1999 [9].

First, the unit compensation costs must be determined as

$$
\sum_{q=m+1}^{n} u_{i q} \overline{\bar{a}}_{q}^{j}=c_{i}^{j}, i, j=\overline{1, m}
$$

where $u_{i q}$-product $i$ costs for damage compensation of waste $q$ emission; 
$c_{i}^{j}-i$ product costs for damage compensation due to all harmful emissions during one-unit production $j$. The total product costs compensation $i, u_{i}$ are

$$
\sum_{q=1}^{m} c_{i}^{j} x_{j}=u_{i}, i=\overline{1, m}
$$

The final good $i$ "purified" from the obligation to compensate the damage $\bar{y}_{i}$ is

$$
\bar{y}_{i}=y_{i}-u_{i}, i=\overline{1, m}
$$

Accordingly, a total "purified" final good $\bar{y}_{i}$ is

$$
\bar{y}=\sum_{i=1}^{m} \bar{y}_{i}
$$

\section{Results and Discussion}

Hereby it can be concluded that the resources' decrease using for environment damage prevention and environmentally-oriented activities in the traditional final good can only create a visibility of resources' growth for consumption and accumulation because more and more they will be spent for losses compensation from the pollution, and the real consumption and accumulation in the national economy will be reduced. Therefore, the "purified" final good, i.e. its traditional value minus costs compensation more clearly reflects the nature of socio-economic development of the country.

The dual nature of the eco technological renovation related to a compensation costs decrease must be noted. Such duality can be illustrated by possible options of researched model use:

1) The technological processes improving associated with the introduction of resource-saving, low-waste technologies and environmental innovations.

If the value $a_{q}^{j}$ is lower at constant values $\bar{a}_{q}^{j}$, the values $\overline{\bar{a}}_{q}^{j}$ will be lower as well as the values $c_{i}^{j}$ will lower too.

2) The effectiveness increasing of pollution preventing and environmental activities.

If the values $\bar{a}_{q}^{j}$ are higher at constant $a_{q}^{j}$, the values $\overline{\bar{a}}_{q}^{j}$ are lower therefore the values $c_{i}^{j}$ are lower too.

For the environmentally friendly technologies transition in the European Union the Best available technology directive (or just BAT) is implemented. Logically, the BAT use relates to both mentioned approaches to eco technological update. The EU industry reference books on BAT has developed and implemented to cover production processes (technologies) relating to specific sectors of the economy. The strategy of the eco technological reasoning with combination of the step process of social environmental quality standards' achievement is disclosed [10]. Each new level achievement should be ensured using expensive BAT. In the process of financial and technical measures implementation for social standards' achievement the green technologies' market must develop (the BAT use to the environment friendly technologies implementation). For each 
stage of the BAT use it is advisable to form the corresponding version of the modified input-output model. Because of such model implementation the environmental and economic damage decreasing will be affected by the eco and technological parameters' improvement and the positive impact of the economic structure on the environment.

\section{Conclusions}

At present, the needs of economic growth in the resources of most countries no longer coincide with the available opportunities, hence, increasing the load on the environment, which results in the deterioration of the quality of natural capital, social conflicts, poverty and hunger. The way out of this crisis is a green economy designed to achieve harmony between the economy and the environment [11]. Thus, in the transition to a green economy, the dynamics of the socio-economic growth will be more adequately characterized by purified macroeconomic indicators such as GDP and final good. The convergence of traditional and macro purified values will occur as they approach to mass use of environment friendly technologies. To assess the achievement degree of target indicators of green economy development the environmental and technological audit could be used [12]. To calculate the green economy development for example for Russia on the basis of proposed modified Leontief-Ford model national statistics or State report materials on the environment and economic development can be used [13] [14]. In our view, the proposed approaches can also be used for green growth evaluation in other countries, including the Asia-Pacific region.

The identified issues in this article open new perspectives for discussion, unresolved issues and suggestions:

1) In the transition to a green economy for the application of this modified input-output model, it is necessary to develop uniform methodological approaches to the assessment and measurement of environmental costs, damage from environmental pollution. This is necessary so that when carrying out similar calculations in different countries of the world unified principles and common approaches are used to measure the negative impact of economic activity on nature.

2) It is also necessary to develop uniform methodological approaches to assess damage and possible losses as a result of climate change in the context of certain types of economic activities (industry, construction, agriculture and forestry, housing and communal services, etc.). This is necessary to develop common approaches and mechanisms to regulate the low-carbon economy within the framework of the Paris Climate Agreements [15], the creation and use of climate funds.

3) To implement this model and conduct practical calculations on its basis, statistics of indicators characterizing the environmental intensity of production, i.e. consumption of natural resources, energy, emissions and discharges of harmful substances, waste generation, greenhouse gas emissions per unit of output, as well as statistical indicators that characterize "net savings", i.e. processes of 
"wear and tear" of natural capital, exhaustion of natural resources for environmental adjustment of GDP.

4) International cooperation of universities and research centers is needed to carry out calculations for one or several countries and regions of the world on the basis of a commensurate system of environmental, economic and climatic indicators.

\section{Acknowledgements}

The paper is prepared by the financial support of the Russian Foundation for Basic Research (RFBR), project N 16-22-03001 and project N 17-02-00249.

\section{References}

[1] Shmelev, S.E. (2012) Economic Models and the Environment: Input-Output Analysis. In: Ecological Economics. Springer, Dordrecht, 87-114. https://link.springer.com/chapter/10.1007/978-94-007-1972-9_6 https://doi.org/10.1007/978-94-007-1972-9

[2] Thang, T.N., Dung, N.T. and Hoang, N.V. (2013) Adaptability in Agriculture and Forestry Activities in Huong Son Commune, Vietnam. Journal of Forest and Livelihood, 11, 82-93. https://doi.org/10.3126/jfl.v11i1.8614

[3] Lukyanchikov, N. and Potravny, I. (2014) Economics and Natural Resource Management. Textbook for University Students, 4th Edition, Revised and Enlarged Extra, UNITY-DANA, Moscow, 688 p.

[4] UNEP (2011) Towards a Green Economy: Pathways to Sustainable Development and Poverty Eradication. http://www.unep.org/greeneconomy

[5] Leontiev, V. and Ford, D. (1972) Intersectoral Analysis of the Effect of Economic Structure on Environment. Ekonomika I Matematicheskiye Metody, 3, 370-399.

[6] Gusev, A. and Bizyarkina, E. (2009) Improvement of Methods of Economic Evaluation of Health Damage from Air Pollution. Nature Management Economics, 2, 134-149.

[7] Nikaido, H. (1972) Convex Structures and Economic Theory. Mir., (Moscow, 514 p.

[8] Aganbegyan, A.G. and Granberg, A.G. (1968) Economic-Mathematical Analysis of Input-Output Balance of the USSR. Mysl, Moscow, $354 \mathrm{p}$.

[9] Vershkov L.V. (1999) The Methodology of Environmental Damage Prevention. State Committee of the Russian Federation for Environmental Protection, Moscow.

[10] Potravny, I.M., Gassiy, V.V., Chernogradsky, V.N. and Postnikov, A.V. (2016) Social Responsibility of Mining Companies in the Territory of Traditional Nature Management as a Basis for Partnership between the Government, Business and Indigenous Peoples of the North. Arctic. Ecology and Economy, 2, 56-63.

[11] Gassiy, V. (2015) Role of the Public-Private Partnership in the Green Growth of the Regional Economics. Gorizonti Ekonomiki, 5, 38-43.

http://elibrary.ru/item.asp?id=24313848)

[12] Ganbat, K., Popova, I. and Potravnyy, I. (2016) Impact Investment of Project Financing: Opportunity for Banks to Participate in Supporting Green Economy. Baltic Journal of Real Estate Economics and Construction Management, Walter de Gruyter $\mathrm{GmbH}, 4$, 69-83. https://doi.org/10.1515/bjreecm-2016-0006

[13] Surinov, A.E. and Baranov, A.F. (2015) Russian Statistical Yearbook. Rosstat, Moscow, $424 \mathrm{p}$. 
[14] Environmental Impact Assessment (EIA). Official Portal Ministry of Natural Resources and Environment (NRE) of Malaysia. http://www.doe.gov.my/eia/

[15] Paris Agreement: Essential Elements. http://unfccc.int/paris_agreement/items/9485.php 